\title{
Estimating Adult Mortality in Cameroon from Census Data on Household Deaths: 1976-1987
}

\author{
By \\ Martin W Bangha \\ University of Pennsylvania, USA
}

\begin{abstract}
:
Many African countries lack conventional data sources for systematic assessment of adult mortality. Studies of mortality in Cameroon have mainly been concerned with infant and child survival, while levels and structure of adult mortality have rarely been investigated. This paper employs the Generalized Growth Balance method to estimate adult mortality in Cameroon using data from 1976 and 1987 censuses. More specifically, we use data on household deaths during the 12 months preceding the 1976 and 1987 censuses to assess the adult mortality situation in Cameroon prior to the onset of HIV/AIDS pandemic. Results suggest that overall adult mortality in Cameroon prior to the HIV/AIDS era was high even by African standards. Ignoring potential methodological and data differences, a comparison of age-specific death rates from the two censuses to those from the recent DHS results portray a recent increase in mortality during the peak productive and reproductive years. However, a complete and reliably operational vital registration system remains the ultimate solution to estimating and fully understanding the trends in adult mortality. In the meantime, consistently collecting census data on household deaths can enhance knowledge and inform policy intervention.
\end{abstract}

Keywords: Adult mortality, completeness of deaths, indirect techniques, HIV/AIDS pandemic

Résumé

La quasi-totalité des études sur la mortalité au Cameroun, ainsi que les efforts déployés ont été focalisé sur l'amélioration de la mortalité infantile et juvénile. Les données conventionnelles pour l'évaluation systématique de la mortalité des adultes manquent encore. Dans cet article, nous utilisons la méthode généralisée de croissance équilibrée avec les données des recensements des 1976 et 1987 pour évaluer la situation de mortalité des adultes au Cameroun. Sauf pour la mortalité infantile et juvénile, les résultats obtenus montrent que la mortalité des adultes est restée inchangée au cours de la décennie précédant l'avènement du HIV/SIDA. Une comparaison des taux de la mortalité par age pour la période considérée à ceux des résultats du EDS II et III, dépeignent une augmentation récente de la mortalité des personnes aux ages productifs et procréatifs. Les données du troisième recensement, une fois rendu publique, nous permettront éventuellement de se situer surcette tendance. 


\section{Introduction}

Reducing mortality in Africa remains a major goal of public health and development efforts. Following substantial investments in medical technology and public health interventions among other factors, dramatic improvements in mortality were recorded during the latter half of the 20th century, resulting in widespread extension of human lifespan beyond past predicted levels in most African countries! Improvements were particularly impressive in child mortality rates as recorded since the 1960s (Hill et al. 1999; Hill and Pebley 1989; Wilmoth 2000). However, mortality at the turn of the 21st century remains disturbingly high in most African countries! Moreover, in recent years, stagnation or reversals of mortality declines have been observed in many African countries. Current assessments of under-five mortality (U5M) suggest that results of the previous decades of focused efforts to reduce mortality are gradually being eroded (Ahmad et al. 2000; Walker et al. 2002; Hill 1993; Zuberi et al. 2003).

Considerable efforts and resources in most developing countries, and Cameroon in

\footnotetext{
${ }^{1}$ Explaining the dramatic improvements in mortality during the $20^{\text {th }}$ century has been a subject of intensive scholarly debate and research over the past three to four decades; particularly as regards the role of economic development and public/personal health measures in the process. Yet, there is no consensus as to the relative importance of the different factors. Preston's (1975) groundbreaking work remains the comerstone of medical innovations and public health measu res while proponents of nutritional influence (see Fogel 2004) continue to emphasize the historical importance of rising incomes on living standards (nutrition). African countries however, seem to have benefited greatly from medical technology and public health interventions thanks to the diffusion of innovations (see Easterlin 2004 and Soares 2007)
}

particular, have been justifiably devoted to the study of, and struggle to curb mortality at the lower extreme ages where mortality risks are known to be particularly high. This is also based on the conventional wisdom that investing in the health and well-being of children is an investment in the future development of the population. In recent years, adult mortality has been recognized as a serious threat to child survival and welfare. Increasing literature on the dynamics of poverty requires a better understanding of prime-age adult mortality because of the potential effects on household behavior and welfare. For instance, recent evidence suggests that children who have lost their parents are at risk for worse schooling and health outcomes (Case et al. 2004; Case and Ardington 2006; Ainsworth et al. 2005; Noumbissi et al. 2005; McDaniel and Zulu 1996). Moreover, in the current context of mounting HIV/AIDS prevalence, a better understanding of the adult mortality situation is crucial for health and development planning, since human capital is highly specialized, scarce and not easily replaceable. .

\section{Literature Review and Theoretical Framework}

Many African countries continue to lack conventional data for systematic assessment of adult mortality. In the absence of reasonably operational vital registration systems, censuses and surveys remain the main source of demographic information on mortality. The use of censuses and surveys requires considerable reliance on indirect 
Martin W Bangha: Estimating Adult Mortality in Cameroon from Census Data on Household Deaths:

measurement techniques, which are limited in terms of the degree of accuracy. The cornerstone in the study of mortality under such circumstances has been the analytical tools pioneered by Brass and his scholars (Brass and Hill 1973; Brass 1975; Hill 1977; Hill and Trussell 1977) over three decades ago that have subsequently been refined and improved (Timaeus 1992; UN 1983) and are being continuously evaluated when and where minimum data are available (Blacker 2004; Timaeus 1999; Timaeus and Jasseh 2004; Gakidou and King 2006; Stanton et al. 2000). Of these analytical tools, the technique for estimating childhood mortality has been most successful and universally accepted. For this reason, the two requisite questions on number of children ever born and number surviving to a woman by age have become standard for virtually all population censuses and surveys across Africa and in many other data-deficient settings? Thanks to this technique, a great deal has been uncovered about the causes and underlying determinants of child mortality, and ways to prevent childhood deaths in African countries, and developing countries in general.

On the other hand, attempts at developing techniques for measurement of adult mortality have been more problematic, partly because of the relatively rare nature of the adult deaths (Preston et al. 2001) relative to childhood deaths. In effect, given the relative

\footnotetext{
${ }^{2}$ Mau ritius is the lone (kn own) exception with an es tablished reputation of a "well-managed" and operational vital registration system. In effect, Mauritius seems so confident of its system that they have completely ignored the call to include Brass-type questions in their censuses and surveys.
}

infrequency of adult events, data on a large sample or on events over a long reference period are necessary in order to allow for a precise measure to be obtained. Also, the likelihood of undercounting and multiple reporting is quite common due to the difficulty of identifying an appropriate informant for reliable information on adult deaths, unlike childhood deaths whose details are more readily provided by their mothers (Timaeus 1991; Lopez et al. 2002). In order to circumvent such difficulties, alongside those associated with direct estimation of mortality in developing countries, numerous techniques have been proposed for the measurement of adult mortality. Unfortunately, none has so far acquired the widespread recognition typical of the technique for estimating childhood mortality.

\section{Preston (1996) provides a} comprehensive review of measurement techniques for overall mortality based on an assessment of all mortality-related studies published in Population Studies from its inception in 1947 up to 1995. Similar reviews by Timaeus (1991) and Hill et al. (2005) have discussed some of the existing indirect or "unconventional" methods for estimation of adult mortality in developing countries where reliable and complete vital registration systems are lacking. Preston (1996), while acknowledging that new methods featured prominently among the key achievements of demography during the post-war period, concludes that improved methods for the assessment of adult mortality remain a major part of the unfinished business for demography. 
Timaeus (1991) suggests a need to adopt a more eclectic approach in trying to improve knowledge of adult mortality in developing countries; that the assessment of the most appropriate measures and methods should be done at the country level. Hill et al. (2005) conclude that adult mortality can be represented by partially registered deaths or deaths by age recorded in censuses on condition that the sources are evaluated and where need be, adjusted by the use of death registration methods.

Prominent among adult mortality techniques are the census-based death distribution technique or the growth balance approach. While these techniques remain relatively untested and hence, not extensively accepted, several rounds of African censuses have progressively collected requisite information for their application (e.g. household deaths 12 months to census) that have not been systematically analyzed. Recently one of the proponents and pioneer of these indirect techniques has initiated a review of the death distribution techniques for performance and sensitivity of estimates (Hill and Cho 2004) to the use of different age ranges for adjustment (Hill and Thomas 2007). In the initial phase of this evaluation, they have opted first for testing the methods under ideal circumstances where requisite data are essentially complete. In this paper, we extend the evaluation of the technique to a particular setting where requisite data are believed to be essentially incomplete.
Cameroon is typical of many African countries where basic indicators of health and mortality are not yet commonly available. Studies of mortality in Cameroon have mainly been concerned with infant and child survival, while levels and structure of adult mortality have rarely been investigated. One major challenge in recent years is the mounting prevalence of HIV/AIDS that has severely jeopardized survival chances. According to current statistics by the UNAIDS (2006), Cameroon has been experiencing one of the more serious epidemics in Central Africa. The first documented AIDS cases in Cameroon were in 1987 (MSP et OMS 1989). Current adult prevalence rate based on pregnant women at antenatal clinics is about $11 \%$ while a recent household survey estimated that national HIV prevalence in 2004 at $5.5 \%$ (UNAIDS 2006). Despite strong interest in, and common wisdom about the impact of HIV/AIDS on adult mortality, absence of conventional and reliable data severely constrains attempts to quantify deaths attributable to AIDS. Moreover, an understanding of the structural impact of this pandemic requires some information on mortality prior to the onset. It is the goal of the current paper to provide this baseline assessment of adult mortality in Cameroon.

Specifically, Hill's (1987) variant of the death distribution methods, applicable to non-stable populations is applied to the 1976 and 1987 census data. The data are evaluated and based on the adjustment factors obtained; reported household deaths and census counts are adjusted to produce corresponding life tables for 
Martin W Bangha: Estimating Adult Mortality in Cameroon from Census Data on Household Deaths:

Cameroon. Also, we examine the direct estimates to see how they compare with similar estimates from recent sources. To assess the performance of the technique, the potential implication of several assumptions (in relation to the coverage of household deaths) on possible estimates of adult mortality is examined. Three sets of adult mortality estimates are generated on the basis of three assumptions: One is based on household deaths in 1986-87 under the assumption that the resultant age-specific mortality rates (ASMR) are observed all through the intercensal period, another based on a similar assumption for 1976 ASMR, and lastly one based on the average ASMR for the two years (1976-1987). .

\section{Data and Methods}

Among the notable efforts to improve the data environment in Africa is the African Census Analysis Project (ACAP) that has complemented various international organizations and governments through the creation of a unique data archive. This effort has helped prevent the disappearance (due to poor storage) of the 1970 and 1980 rounds of African censuses, and these censuses have become increasingly available to many researchers. For this study, we use the first two censuses of Cameroon available from the ACAP data archive to assess adult mortality in Cameroon. The first census was conducted from April 9-24, 1976 and the second followed 11 years later from April 14-28, 1987. In terms of population estimates, there were 7.6 million and 10.5 millions individuals in 1976 and 1987, respectively. Data are effectively available for 7,429,555 persons from the 1976 census data file, corresponding to the unadjusted census count. On the other hand, data are available for $8,883,643$ persons from the 1987 census data file, which falls short of the unadjusted head count reported for this census (see BCR 1978 and Cameroun 1992 for details).

While no Brass-type questions on survivorship of children were included, a direct question was consistently included on deaths in the household during the past 12 months preceding the census which constitute the mortality inputs for this analysis. A total of about 104,000 household deaths were recorded during the 12 months prior to the 1987 census. There is a slight indication of a male penalty and about $40 \%$ of all deaths pertain to children under age five. Similarly, some 79,300 deaths were reported for the 12 months prior to the 1976 census, $45.9 \%$ of them being children under age 5 . While the percent distribution of the deaths by age and sex could be influenced by the size of each group (age-sex) relative to the total population, these preliminary numbers portray the very high and expected contribution of infants and children to overall deaths in 12 months. These numbers also imply a slight drop in the proportion of infants and children that succumbed to death during their first five years of life.

\section{Methods}

In the absence of reasonably operational vital registration systems, 
African Population Studies Vol. $23 N^{\circ} 2 /$ Etude de la Population Africaine Vol. $23 \mathrm{~N}^{*} 2$

census and survey-based estimation of adult mortality rely heavily on indirect methods that entail use of information on survivorship of close relations and/or census age distribution combined with reported or registered deaths. Because reported household deaths in censuses, are generally believed to be affected by reference period errors, techniques developed (Brass 1975; Preston and Hill 1980; Hill 1987; UN 2002a) for use under such conditions requires some data adjustments. The present analysis employs the generalized growth balance (GGB) technique and examines the potential implications of certain assumptions (particularly in relation to the coverage of household deaths) on possible estimates of adult mortality for Cameroon. This method is most appropriate because it equally serves as an evaluation tool for the data. To obtain the overall estimates of intercensal deaths required for the application of the method, the two-census age distributions are combined with the household deaths reported 12 months prior to each census. The resultant age-specific mortality rates (ASMR) from each census are assumed to prevail all through the intercensal period and applied to the person-years lived to obtain the deaths. By assuming that 1987 ASMR prevail over the intercensal period, an estimate of adult mortality is obtained that should portray the conditions in 1987. Another set of estimates is obtained under a similar assumption for the 1976 ASMR which should provide an idea of the situation in the mid 1970s, and lastly the average of the ASMR for 1976-1987 is used.

The GGB is a death distribution method derived from the basic demographic balancing equation. First pioneered by Brass (1975), the method describes that for an open ended age segment of a closed population (denoted by $\mathrm{x}^{+}$), the birth rate (entries into an age segment) is equal to the growth rate of the segment plus the death rate (departures from that segment). Initially defined only for stable populations, later developments relaxed the assumption of stability (Preston and Hill 1980) given two or more censuses and a further refinement (Hill 1987) is designed to be less sensitive to age misreporting. This latter refinement has been referred to as the generalized growth balance (GGB) method. It focuses on changes in sizes of age groups rather than on changes in cohort sizes with allowance for differences in census coverage and incompleteness of death registration (Preston et al. 2001). By comparing the age distribution of deaths with the age distribution of the surviving it provides an age pattern of mortality for a given reference period. The fundamental assumption here is that the population in question experiences negligible migration during the intercensal period.

Consequently, it is implicitly assumed in the analysis that the population experienced negligible net migration during the intercensal period. Migration is generally a more intricate issue in demographic estimation, since it is particularly unusual to have adequate information on it. Migration can affect a population in the same way mortality does and in some cases may potentially result in greater distortion since it is historically 
Martin W Bangha: Estimating Adult Mortality in Cameroon from Census Data on Household Deaths:

age-, and sex-selective in favor of males in the adult ages. While recognizing that migration may considerably affect the level of estimates, in our view negligible net migration is a reasonable assumption for this period in the history of Cameroon and considering the fact that the analysis are restricted to the national level. In effect, it is only in the late 1990s following the combined political crisis of the early 1990s and mounting economic depression that Cameroon is believed to have witnessed a considerable wave of out-migration likely to have resulted in substantial net migration.

For an idea on the plausibility of this assumption for Cameroon, the UN migration stock database (UN 2002b) provides rough estimates indicating that annual net migration up to the early 1990s was about -0.1 per 1000 population for Cameroon. As such, it is reasonable in this case to assume negligible net migration. While this assumption is plausible for the current analysis, it is particularly important to include migration in the estimation procedure if these analyses were to be extended to areas where net migration is substantial. In this direction, the GGB method has been reformulated (Bhat 2002; Hill and Queiroz 2004) for application to populations that are substantially affected by migration. However, use of these refinements still requires some knowledge of the intercensal age distribution of migrants which are hard to come by.

By implication the basic demographic balancing equation (see Hill
1987 and UN 2002a for details on the derivation) is applied to a segment of the population over any given age x such that:

$$
r(x+)=b(x+)-d(x+) \text {; }
$$

Where $r\left(x^{+}\right), b\left(x^{+}\right)$and $d\left(x^{+}\right)$are respectively, the growth rate, birth rate, and death rate of the population segment age $x$ and above. Birth rate in this case refers to the ratio of the people attaining age $x$ during the reference period to the total person-years lived by the population age $x$ and above. According to model propose by Hill (1987), the basic accounting equation can be transformed into its component rates by the following formula:

$$
\frac{N(x)}{P Y L(x+)}-r(x+)=\frac{D(x+)}{P Y L(x+)}
$$

Where PYL $\left(x^{+}\right)$is the person-years lived by age $x$ and above, $r\left(x^{+}\right)$is the population growth rate at aged $x$ and above, $D(x+)$ is the total deaths at ages $x$ and over. $N(x)$ denotes the number of persons reaching exact age $x$ (or celebrating their $x$ th birthday) during the interval and is estimated geometrically by interpolation of persons in the 5 -year age groups $x-5$ to $x$, and $x$ to $x+5$ of the two census distributions. As mentioned earlier, by comparing the two sides of the foregoing equation, the relative completeness of reported household deaths is estimated. The calculations are then extended to the evaluation of the two successive censuses and subsequently adjusted to produce an age pattern of mortality for a given reference period. 
Another variant of the death distribution techniques is the extinct generations' method that uses data only on registered deaths to reconstruct the cohort size of a particular age by counting all the cohort deaths till it is extinct (Bennett and Horiuchi 1981; 1984). Also referred to as the Bennett-Horiuchi $(\mathrm{BH})$ approach, the method indirectly provides a test of whether data are accurate (UN 2002a). But by definition, it cannot be applied to recent non-extinct generations (Preston et al. 2001). Hill and Choi (2004) have used simulations to evaluate effect of common patterns of data errors on the performance of the GGB and the BH methods. Their simulation results suggest that combining the GGB and $\mathrm{BH}$ method can produce better estimates of death registration completeness. In line with this suggestion, the GGB is first used to estimate census coverage, then the census count is adjusted accordingly to be consistent, and thereafter applying the $\mathrm{BH}$ method to arrive at an adjustment factor for deaths. But prior to applying the techniques and generating mortality estimates, it is appropriate to assess the data quality, particularly the age-sex composition on which the techniques employed relies.

\section{Results}

\section{Data Assessment}

An examination of the percentage distribution of single age (Figure 1) for the two censuses show a general decline as age advances with some considerable amount of heaping suggesting a strong preference for digits 0 and 5 in the reporting of ages.
Such age heaping and digit preference is common in demographic data. The graphical assessment indicates that this age heaping is somewhat similar in both censuses, though age heaping and digit preference appears to be somewhat lower in 1987 compared to 1976. Grouping the data into conventional age groups reveals a steady decline with age. A consistency check on the data that consist of comparing 5 -years and 10-years birth cohorts portray virtually parallel lines with slight indentation for the younger birth cohorts which seems consistent with lower fertility during the intercensal period. There is no crossover to suggest a large intercensal migratory movement or a large undercount in one census relative to the other.

The age-specific sex ratios of the population are consistent with the expected pattern that typically implies more male births than females, with lower mortality during the life course allowing females to eventually catch up with the males towards the young adult ages and outnumber them at the older ages. The sex ratio in the Cameroon census is estimated at 96 males per 100 females for both 1976 and 1987, suggesting a constant fraction of males as a proportion of the total population. By age groups the sex ratios ranges from 104 for the youngest age group

\footnotetext{
${ }^{3}$ The overall sex ratio pertain s to the whole pop ulation (ratio of males to females) while the age-specific sex ratios (or sex ratios for age groups) refers to the ratio of males to females in each 5-year age group. The age-specific sex ratios may vary widely around the overall sex ratio and knowledge of such variation s may be very important for analytical purposes. A low sex ratio (below 100) implies that the population of particular age group is disproportionately female.
} 
Martin W Bangha: Estimating Adult Mortality in Cameroon from Census Data on Household Deaths:

to below 100 by age group 15-19 where it remains through to the older ages. On the whole ignoring slight fluctuations, the pattern of age-specific sex ratios seems consistent with the global picture for Africa (see UN 2004; Shyrock, Siegel and Associates 1976) where sex ratios are generally around 100 for the age range 0 -
14, drop to a little above 90 for the broad age range 15-59, and then drop below 80 thereafter. Also, the age ratios are generally above 90 except above age group 55-59. Departures from the standard expected value of 100 are not large for ages below 60 , a pattern suggestive of relatively reasonable data errors below this age.

Figure 1: Distribution of population by single age, sex and year of census

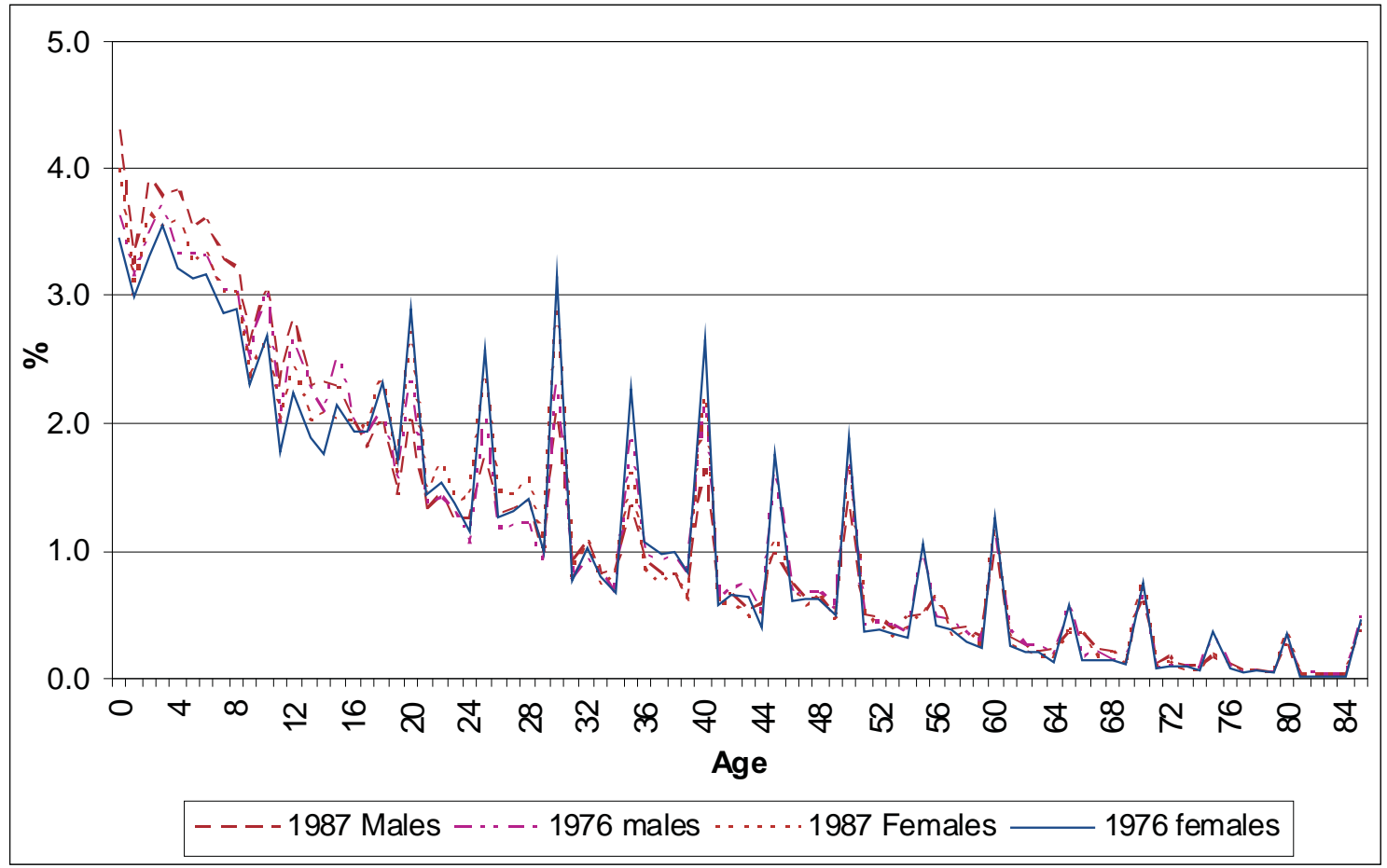

Source: Author's calculations based on the 1976 and 1987 censuses of Cameroon

The overall sex ratio of household deaths reported for the 12 months preceding the 1987 census is 117 males per 100 females which is not significantly different from the 116 obtained for the 12 months prior to the 1976 census. The observed age-specific patterns are indicative of substantial excess male mortality. The sex ratios of reported deaths by age group start at 120 and remain steadily above 100 across age, except for ages 15-44 where the male mortality penalty seems to disappear and resurfaces at the end of the reproductive span (45-49). The pattern is same for the two census years, except that the trough between ages 15-49 is deeper for the first census than for the second. Figure 2 compares the ratio of observed male to female age-specific death rates from the two censuses and provides a 
closely similar picture to that portrayed by the sex ratios of reported deaths pointing to male excess mortality as well as high maternal mortality at the time of the first census that appears to have declined by
1987. A similar pattern emerges from the comparison of ratios of observed ASMR for 1987 to those for 1976 as depicted in Figure 3.

Figure 2: Ratios of male to female age-specific death rates by 5-year age groups

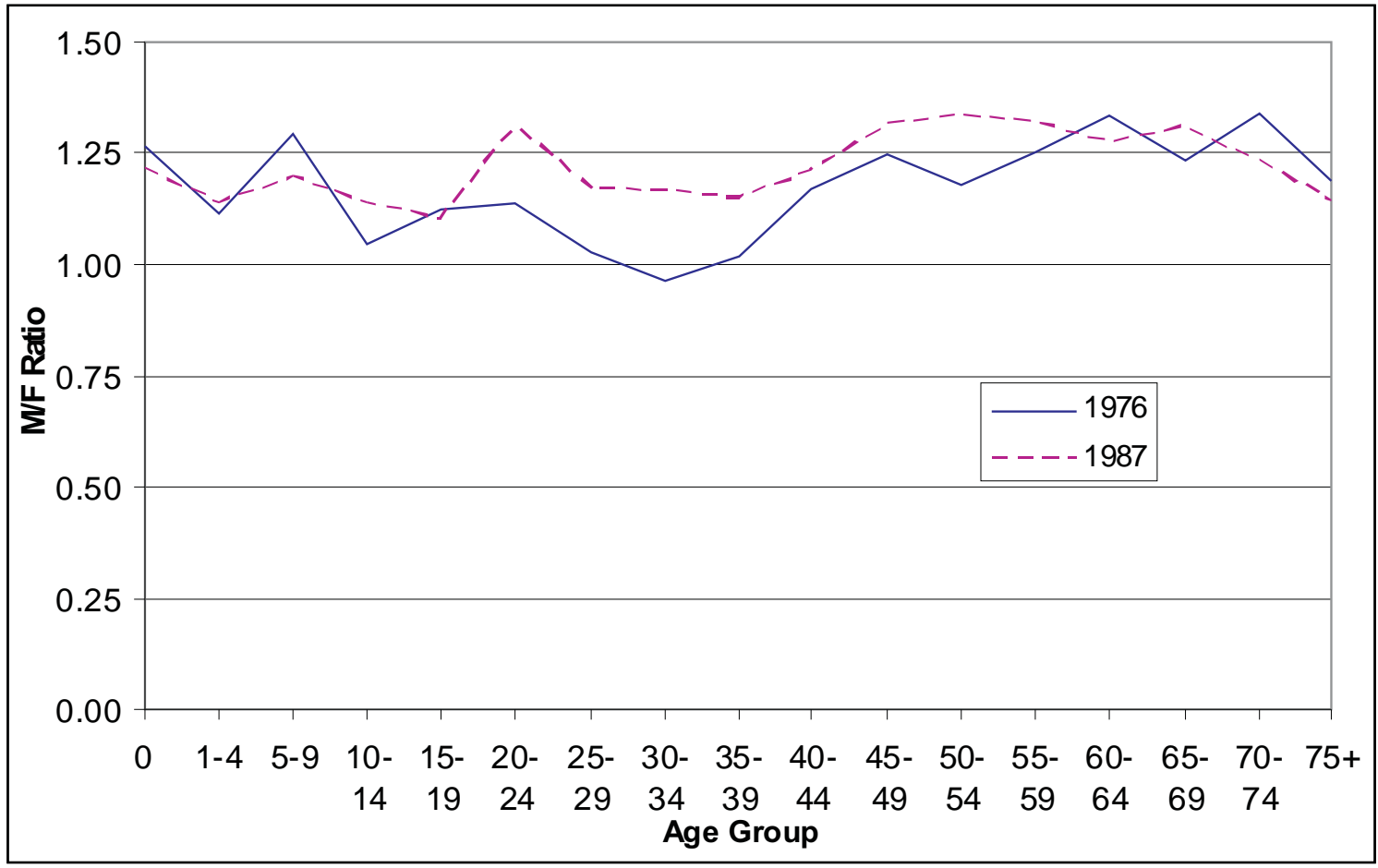

Source: Author's calculations based on the 1976 and 1987 censuses of Cameroon

A key component of the diagnostic checks on census coverage entails examining the intercensal age-specific growth rates (ASGRs). Except for situations where there has been an appreciable net migration, average annual growth rates have seldom been recorded outside the range of 0 to 3\% (Shyrock, Siegel and associates 1976). Rates outside this range may also suggest that one or the other of the censuses was a substantial undercount. We also examined the mean annualized ASGRs and they follow virtually a similar pattern for both sexes. The rate falls a little off this expected range only in one or two cases: females age 35-39, where the ASGR is not very different from zero and age groups 10-14 for both sexes and 0-4 for males where the ASGR is at the upper boundary. The well-known mobile ages likely to be missed by a census are the young adults and to some extent the old adults. The observed trough does not seem consistent with the type of distortion that might be attributable to age-selective migration, since this is observable for both 
Martin W Bangha: Estimating Adult Mortality in Cameroon from Census Data on Household Deaths:

sexes, but steeper for females. This could be partly an attribute of potential downward shifting of persons as a result of age misstatement. Aside from this slight distortion, the growth rates are generally within expected range, implying the data are perhaps fairly good. A better gauge of the growth trend can only be done in a case where there has been a series of preceding censuses. In the absence of such a series, we turn to the GGB to evaluate and generate adjustment factors that allow for consistency between reported deaths and the population denominators.

Figure 3: Ratios of age-specific death rates for 1987 relative to 1976 by sex

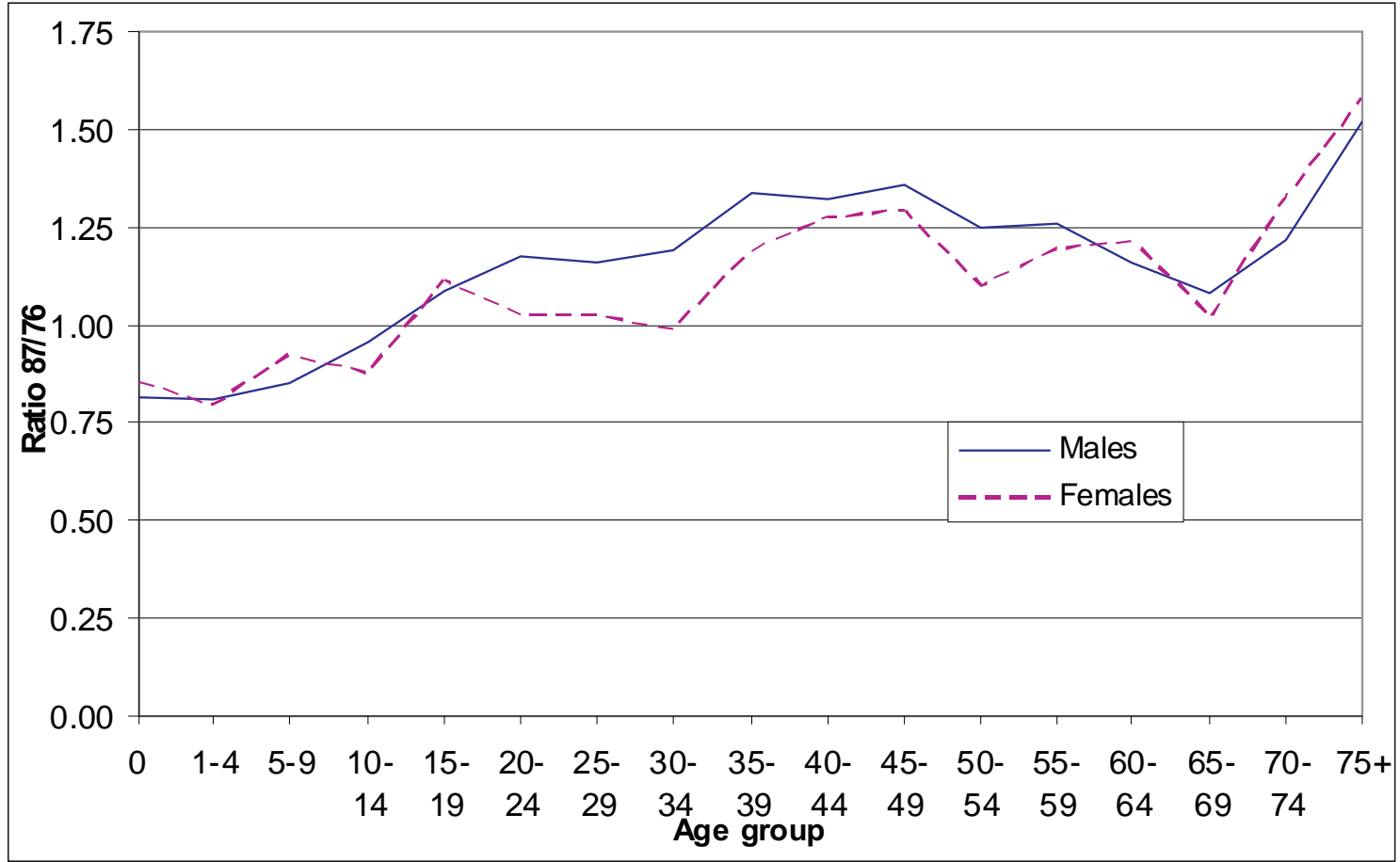

Source: Author's calculations based on the 1976 and 1987 censuses of Cameroon.

Relative completeness of deaths and census enumeration

To minimize errors resulting from frequent exaggeration of the age at death of the elderly, the initial refinement of the growth balance method by Hill (1987) recommends that the completeness parameters be estimated by fitting lines to data points below age 60 . Incidentally, the method is being reviewed for performance and sensitivity of estimates to the use of different age ranges for adjustment. In the preliminary evaluation, Hill and Thomas (2007) opted first for testing the method under ideal circumstances where requisite data are essentially complete. They have compared three alternative age ranges for adjustment (15-55+, 5-65+, and 40-80+) and from the preliminary results, the two 
preferable age ranges are $15-55+$ and $40-$ $80+$. It appears their tilt is in favor of using the latter, which produces relatively stable results in the face of substantial net migration (Hill and Thomas 2007). Except that the age range 15-55+ tends to be affected by substantial net migration, the results are pretty stable as well. Considering the preceding assessment of data for Cameroon, and the awareness that age at death for the elderly is likely to be distorted, especially for these early censuses, the data are fitted to the average age range $15-55+$. In effect, completeness estimates were equally fitted to the 40-80+ age range (results not shown here) but from the outcome, fitting completeness estimates to $40-80+$ does not appear to work well for Cameroon, at least in this case.

Table 1 shows the estimated completeness of reported deaths for the 12 months preceding each census. It should be recalled that deaths are estimated under the assumption that each set of ASMR prevail all through the intercensal period.
Based on these estimates, the reported household deaths prior to the 1987 census seem to approximate fairly complete reporting. Generally household deaths appear to be slightly less completely reported for females than for males. The overall reporting of male deaths based on the 1987 ASMR was about 87\% complete relative to the population count as compared to female deaths estimated at $81 \%$ complete. The male-female differential reporting seems consistent in the two censuses, with a slightly larger difference in the case of 1976 deaths. Under the alternative assumption that 1976 ASMR prevailed all through the intercensal period, the estimated completeness suggest that reported deaths represent a shortfall of close to half of the expected intercensal deaths relative to the population count. This is particularly the case with reported female deaths (59\% complete) as against male deaths $(66 \%$ complete). As noted in Table 1, the application of the GGB and $\mathrm{BH}$ adjusted method (Hill and Choi 2004) produces almost identical estimates of deaths

Table 1: Relative completeness of household deaths reporting in 1976 and 1987 censuses

\begin{tabular}{|c|c|c|c|c|c|c|}
\hline \multirow[b]{3}{*}{$\begin{array}{l}\text { Source of deaths } \\
\text { data }\end{array}$} & \multicolumn{4}{|c|}{$\begin{array}{l}\text { Estimated completeness of } \\
\text { reported deaths }\end{array}$} & \multirow{2}{*}{\multicolumn{2}{|c|}{$\mathrm{k} 1 / \mathrm{k} 2$}} \\
\hline & \multicolumn{2}{|c|}{ Males } & \multicolumn{2}{|c|}{ Females } & & \\
\hline & GGB & $\begin{array}{c}\mathrm{BH} \\
\text { adjusted }\end{array}$ & GGB & $\begin{array}{c}\mathrm{BH} \\
\text { adjusted }\end{array}$ & Male & Female \\
\hline 1987 census. & 0.868 & 0.888 & 0.810 & 0.815 & 1.055 & 1.105 \\
\hline 1976 census & 0.658 & 0.662 & 0.588 & 0.581 & 1.051 & 1.086 \\
\hline $\begin{array}{l}\text { Average 1976-87 } \\
\text { deaths }\end{array}$ & 0.765 & 0.777 & 0.706 & 0.705 & 1.053 & 1.097 \\
\hline
\end{tabular}

Source: Author's computations based on the 1976 and 1987 censuses of Cameroon Notes: $\mathrm{k} 1$ is the completeness of coverage for the 1976 census; $\mathrm{k} 1 / \mathrm{k} 2$ is relative Completeness GGB is generalized growth balance method; $\mathrm{BH}$ is the BennettHoriuchi method 
Martin W Bangha: Estimating Adult Mortality in Cameroon from Census Data on Household Deaths:

The estimates of enumeration completeness also provided ( $\mathrm{k} 1$ and $\mathrm{k} 2$ for the first and second censuses respectively) are relative to one or the other census with the reference census being a simple matter of choice. It is not possible to estimate the completeness parameters for both censuses individually because there is no way to distinguish the situation in which both censuses and deaths are under-reported by precisely the same magnitude from the situation in which both censuses and deaths are completely reported. This is not potentially problematic, since the equal under-reporting in both censuses and deaths cancel out (Preston et al. 2001; UN 2002a). At best, for a known level of deaths reporting in the intercensal period, or if we are able to make informed guesses on its value, it will be possible to estimate $\mathrm{k} 1$ and $\mathrm{k} 2$ individually. In the current situation we do not have sufficient information to venture into informed guesses on the value of death reporting. A convenient way to proceed (UN 2002a) is to ascertain which of the two $k$ values is larger, arbitrarily set this value equal to one and then estimate the other $k$ value by their ratio. Hence if $k 1 / k 2$ $>1$ implies $\mathrm{k} 1>\mathrm{k} 2$, then we assume $\mathrm{k} 1=1$ and $k 2=1 /(k 1 / k 2)$. On the other hand, if $\mathrm{k} 1 / \mathrm{k} 2<1$ then $\mathrm{k} 1<\mathrm{k} 2$, and we set $\mathrm{k} 2=1$ and $k 1=k 1 / k 2$. By setting any of the parameter equal to 1 , we are implicitly assuming a case where the corresponding (reference) census was at least complete.

Following this logic, it is estimated that the 1976 enumeration was apparently more complete relative to the 1987 census. In effect, the estimates show that the 1987 census was about $93 \%$ complete relative to the 1976 census, with the male enumeration estimated at $95 \%$ complete and the enumeration of females at $90 \%$ complete. These findings seem pretty consistent when we considered the different reports from the post enumeration assessment of the two operations. In effect, the estimated undercount level was much larger for the second operation than in the first; an average of $7 \%$ in 1976 as against $12.7 \%$ for the 1987 census.

\section{Adult Mortality Estimates}

Using the estimated adjustment factors obtained, we have adjusted the reported household deaths and census counts accordingly before generating the corresponding life tables for Cameroon. The general age pattern of mortality depicted by the adjusted age-specific mortality rates (ASMR) are presented in Figures $4 \mathrm{a}$ and $4 \mathrm{~b}$. The age pattern is consistent with the general expectation where mortality is approximately " $\mathrm{U}$ shaped" reflecting high mortality during childhood and late adulthood. Both figures (males and females respectively) portray some possible intercensal declines in mortality among the under 15 years old. But for ages above 15, the only visible sign of mortality gains is for females, whereas the ASMR for males above 15 are virtually identical between 1976 and 1987. 
Figure 4a: Male adjusted age-specific mortality rates for 1976 and 1987

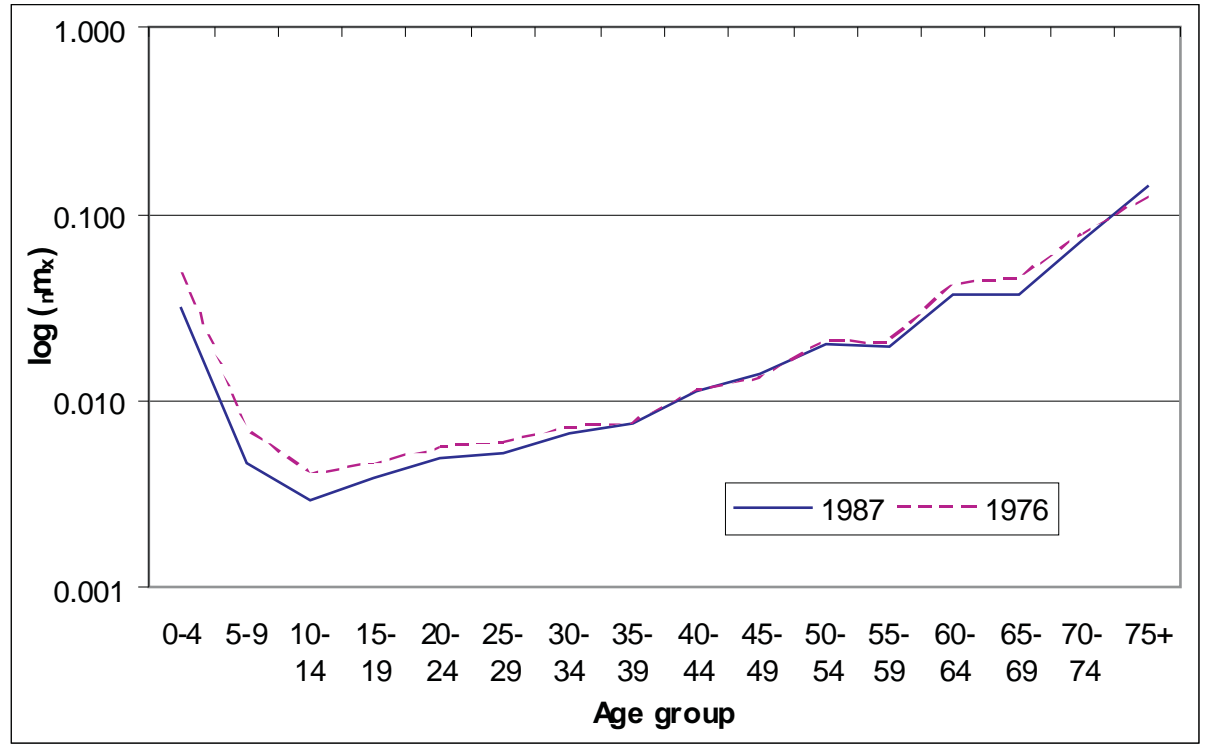

Figure 4b: Female adjusted age-specific mortality rates for 1976 and 1987

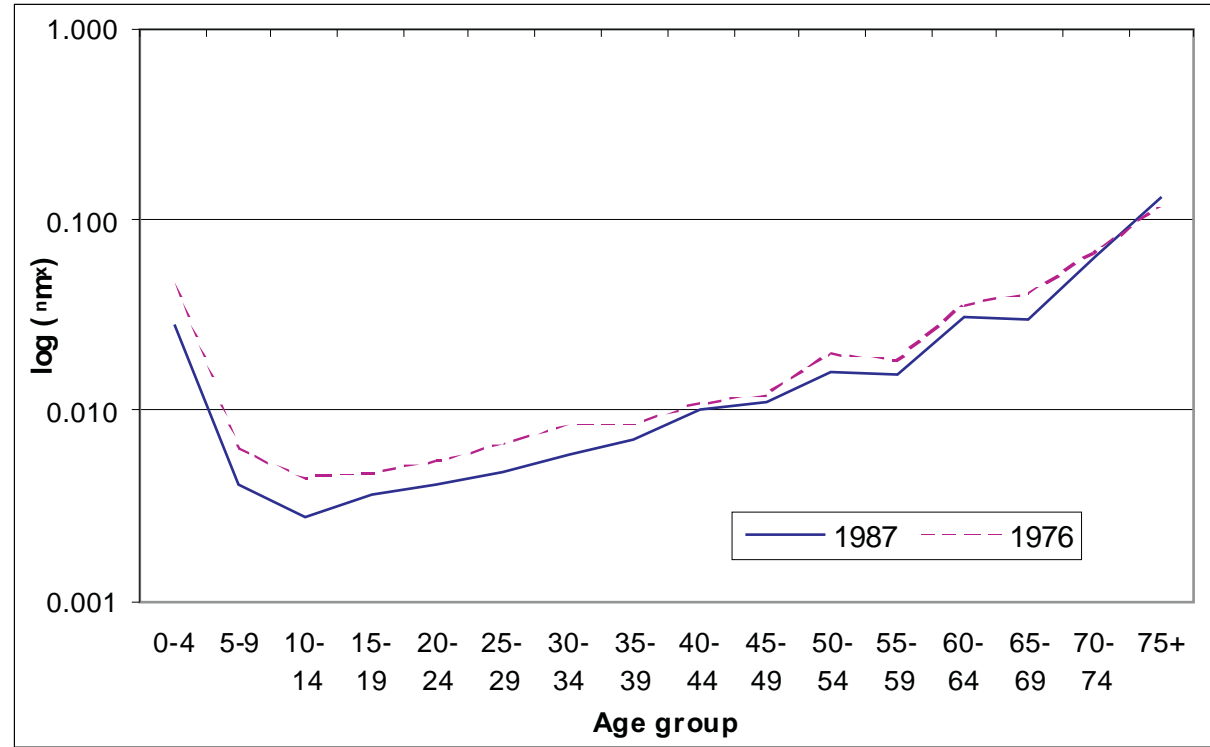

Source: Author's calculations based on the 1976 and 1987 censuses of Cameroon.

An appropriate way of quantifying adult mortality risk in a population based on the life table approach is to express it as the conditional probability of dying between ages 15 and 60, denoted conventionally as 45Q15. In other words, this gives the proportion of persons aged 15 years old who will die before their 60th 
Martin W Bangha: Estimating Adult Mortality in Cameroon from Census Data on Household Deaths:

anniversary under given mortality conditions. Table 2 presents the observed and adjusted probabilities (45Q15) which are further broken down into the conditional probabilities of dying between age 15 and 40 (25Q15) and between age 40 and 60 (20Q40). This should allow for a comparison of young adult mortality to that of older adults. The estimates for each sex are different by whether the censuses are adjusted for the relative undercount or not, but they are nevertheless quite close. Using the unadjusted census counts produces simultaneously a slightly higher percentage completeness of deaths and a higher adult mortality estimate.
On the whole, the adjusted estimates suggest that under the 1987 mortality conditions, about $37 \%$ of Cameroon males reaching age 15 were unlikely to celebrate their 60 th anniversary. A slightly smaller proportion is obtained for females (32\%), which imply a $15 \%$ excess adult male mortality relative to adult female mortality. As expected the mortality risk increase generally with age from age 15 but the slope is steeper after age 40 . The probability of dying between ages 40 and 60 is almost twice that between age 15 and 40. The $\mathrm{BH}$ adjusted estimates are lower but consistent with those produced by the GGB adjustment.

Table 2: Probability of dying for adults between exact ages 15 and 60 (45Q15), for young adults between exact ages 15 and 40 (25Q15), and old adults between exact ages 40 and 60 (20Q40) by sex, Cameroon 1976-1987

\begin{tabular}{|c|c|c|c|c|c|c|}
\hline \multirow{3}{*}{$\begin{array}{l}\text { Indicator and } \\
\text { Method of } \\
\text { Adjustment }\end{array}$} & \multicolumn{3}{|c|}{ Males } & \multicolumn{3}{|c|}{ Females } \\
\hline & \multicolumn{3}{|c|}{ Source of Deaths Data } & \multicolumn{3}{|c|}{ Source of Deaths Data } \\
\hline & $\begin{array}{c}1987 \\
\text { Census }\end{array}$ & $\begin{array}{c}1976 \\
\text { Census }\end{array}$ & $\begin{array}{l}\text { Average. } \\
1976-87\end{array}$ & $\begin{array}{c}1987 \\
\text { Census }\end{array}$ & $\begin{array}{c}1976 \\
\text { Census }\end{array}$ & $\begin{array}{l}\text { Average. } \\
1976-87\end{array}$ \\
\hline \multicolumn{7}{|l|}{ 25Q15 } \\
\hline Observed & 0.1150 & 0.0964 & 0.1067 & 0.0988 & 0.0929 & 0.0960 \\
\hline GGB adjusted & 0.1312 & 0.1428 & 0.1371 & 0.1206 & 0.1528 & 0.1331 \\
\hline $\mathrm{BH}$ adjusted & 0.1253 & 0.1387 & 0.1320 & 0.1143 & 0.1489 & 0.1277 \\
\hline \multicolumn{7}{|l|}{$20 Q 40$} \\
\hline Observed & 0.2426 & 0.1944 & 0.2204 & 0.1921 & 0.1633 & 0.1788 \\
\hline GGB adjusted & 0.2738 & 0.2800 & 0.2778 & 0.2316 & 0.2616 & 0.2433 \\
\hline $\mathrm{BH}$ adjusted & 0.2626 & 0.2726 & 0.2683 & 0.2204 & 0.2553 & 0.2341 \\
\hline \multicolumn{7}{|l|}{$45 Q 15$} \\
\hline Observed & 0.3297 & 0.2721 & 0.3035 & 0.2719 & 0.2411 & 0.2576 \\
\hline GGB adjusted & 0.3691 & 0.3828 & 0.3768 & 0.3243 & 0.3745 & 0.3440 \\
\hline $\mathrm{BH}$ adjusted & 0.3549 & 0.3735 & 0.3649 & 0.3095 & 0.3662 & 0.3318 \\
\hline
\end{tabular}

Source: Author's computations based on the 1976 and 1987 censuses of Cameroon 
As indicated previously, the adjusted ASMR and the corresponding life table values, 45Q15, were also estimated under the assumption that 1976 rates prevailed all through the intercensal period. Comparing the estimates with those based on the 1987 rates should provide some rough indication of the adult mortality trends during this period. The results suggest that adult male mortality in Cameroon probably stagnated during the intercensal period at their 1976 levels. In particular, the probability of dying between ages 15 and 60 under the 1976 mortality conditions estimated at $38 \%$ is so close to the corresponding estimate (37\%) under the 1987 mortality conditions. On the other hand, adult female survival probability had apparently improved during the same period, from about $63 \%$ in 1976 which was similar to that of males, to $68 \%$ in 1987 . This is consistent with the results presented in the data assessment section where an observed trough in the 1976 ratio of male to female ASMRs for the reproductive years disappears in 1987.
An alternative life table measure of adult mortality is the average expected remaining years of life at age 15 (Table 3). Based on the adjusted mortality conditions (ASMR) for 1976, the average expectation of life at age 15 (e15) was almost similar for both sexes (about 47.3 years as against 47.9 for females). The corresponding estimate based on the 1987 conditions suggest an increasing sex difference of about 2 years in favor of females (50.2 years) while that of males remained virtually at the same level (47.9 years) all through the intercensal period. However, given that this is a cumulative measure of mortality there are signs of a slight general increase in life expectancy for males as average remaining years at age 5 (e5) went up from 54.4 to 56.0 years. Again the increase for women is more (from 55.2 to 58.3 years). Generally the improvements in average remaining years turn to be minimal for both sexes towards the higher ages. 
Martin W Bangha: Estimating Adult Mortality in Cameroon from Census Data on Household Deaths:

Table 3a: Male and female life tables based on adjusted 1987 deaths

\begin{tabular}{|c|c|c|c|c|c|c|c|c|}
\hline \multirow[b]{2}{*}{$\begin{array}{l}\text { Age } \\
\text { group }\end{array}$} & \multicolumn{4}{|c|}{ Males } & \multicolumn{4}{|c|}{ Females } \\
\hline & $\begin{array}{c}\text { ASMR } \\
{ }_{5} \mathrm{~m}_{\mathrm{x}} \\
\end{array}$ & $\begin{array}{c}\text { Probability } \\
\text { of dying } \\
{ }_{5} q_{x}\end{array}$ & $\begin{array}{c}\text { Survivors } \\
\text { to age } \mathrm{x} \\
\mathrm{I}_{\mathrm{x}} \\
\end{array}$ & $\begin{array}{c}\text { Life } \\
\text { expectancy } \\
e_{\mathrm{x}} \\
\end{array}$ & $\begin{array}{c}\text { ASMR } \\
{ }_{5} \mathrm{~m}_{\mathrm{x}} \\
\end{array}$ & $\begin{array}{c}\text { Probability of } \\
\text { dying } \\
5 q_{x}\end{array}$ & $\begin{array}{c}\text { Survivors } \\
\text { to age } x \\
I_{x} \\
\end{array}$ & $\begin{array}{c}\text { Life } \\
\text { expectancy } \\
e_{\mathrm{x}} \\
\end{array}$ \\
\hline $0-4$ & 0.0313 & NA & NA & NA & 0.0282 & NA & NA & NA \\
\hline $5-9$ & 0.0046 & 0.0228 & 1.0000 & 56.0 & 0.0041 & 0.0203 & 1.0000 & 58.3 \\
\hline $10-14$ & 0.0029 & 0.0145 & 0.9772 & 52.2 & 0.0027 & 0.0136 & 0.9797 & 54.5 \\
\hline $15-19$ & 0.0038 & 0.0189 & 0.9630 & 47.9 & 0.0037 & 0.0182 & 0.9664 & 50.2 \\
\hline $20-24$ & 0.0049 & 0.0244 & 0.9448 & 43.8 & 0.0040 & 0.0199 & 0.9488 & 46.1 \\
\hline $25-29$ & 0.0053 & 0.0260 & 0.9218 & 39.9 & 0.0048 & 0.0237 & 0.9300 & 41.9 \\
\hline $30-34$ & 0.0066 & 0.0322 & 0.8978 & 35.9 & 0.0060 & 0.0295 & 0.9079 & 37.9 \\
\hline $35-39$ & 0.0077 & 0.0376 & 0.8689 & 32.0 & 0.0071 & 0.0349 & 0.8812 & 34.0 \\
\hline $40-44$ & 0.0114 & 0.0553 & 0.8362 & 28.1 & 0.0100 & 0.0486 & 0.8505 & 30.1 \\
\hline $45-49$ & 0.0137 & 0.0660 & 0.7900 & 24.6 & 0.0110 & 0.0537 & 0.8091 & 26.5 \\
\hline $50-54$ & 0.0199 & 0.0946 & 0.7378 & 21.2 & 0.0158 & 0.0760 & 0.7657 & 22.9 \\
\hline $55-59$ & 0.0193 & 0.0922 & 0.6680 & 18.1 & 0.0156 & 0.0750 & 0.7075 & 19.6 \\
\hline $60-64$ & 0.0372 & 0.1702 & 0.6064 & 14.7 & 0.0310 & 0.1440 & 0.6544 & 15.9 \\
\hline $65-69$ & 0.0366 & 0.1677 & 0.5032 & 12.2 & 0.0297 & 0.1384 & 0.5602 & 13.2 \\
\hline $70-74$ & 0.0722 & 0.3058 & 0.4188 & 9.2 & 0.0623 & 0.2695 & 0.4827 & 9.9 \\
\hline $75+$ & 0.1404 & ----- & 0.2908 & 7.1 & 0.1306 & ----- & 0.3526 & 7.7 \\
\hline
\end{tabular}

Source: Author's computations based on the 1976 and 1987 censuses of Cameroon

Table 3b: Male and female life tables based on adjusted 1976 deaths

\begin{tabular}{|c|c|c|c|c|c|c|c|c|}
\hline \multirow[b]{2}{*}{$\begin{array}{l}\text { Age } \\
\text { group }\end{array}$} & \multicolumn{4}{|c|}{ Males } & \multicolumn{4}{|c|}{ Females } \\
\hline & $\begin{array}{c}\mathrm{ASMR} \\
{ }_{5} \mathrm{~m}_{\mathrm{x}} \\
\end{array}$ & $\begin{array}{c}\text { Probability } \\
\text { of dying } \\
{ }_{5} q_{x}\end{array}$ & $\begin{array}{c}\text { Survivors } \\
\text { to age } x \\
I_{x}\end{array}$ & $\begin{array}{c}\text { Life } \\
\text { expectancy } \\
e_{x} \\
\end{array}$ & $\begin{array}{c}\mathrm{ASMR} \\
{ }_{5} \mathrm{~m}_{\mathrm{x}} \\
\end{array}$ & $\begin{array}{c}\text { Probability } \\
\text { of dying } \\
{ }_{5} q_{x}\end{array}$ & $\begin{array}{c}\text { Survivors } \\
\text { to age } \mathrm{x} \\
\mathrm{I}_{\mathrm{x}}\end{array}$ & $\begin{array}{c}\text { Life } \\
\text { expectancy } \\
e_{x} \\
\end{array}$ \\
\hline $0-4$ & 0.0492 & NA & NA & NA & 0.0469 & NA & NA & NA \\
\hline $5-9$ & 0.0071 & 0.0348 & 1.0000 & 54.4 & 0.0062 & 0.0304 & 1.0000 & 55.2 \\
\hline $10-14$ & 0.0040 & 0.0198 & 0.9652 & 51.3 & 0.0043 & 0.0214 & 0.9696 & 51.8 \\
\hline $15-19$ & 0.0046 & 0.0227 & 0.9461 & 47.3 & 0.0046 & 0.0228 & 0.9488 & 47.9 \\
\hline $20-24$ & 0.0055 & 0.0272 & 0.9246 & 43.3 & 0.0055 & 0.0269 & 0.9272 & 43.9 \\
\hline $25-29$ & 0.0060 & 0.0293 & 0.8995 & 39.4 & 0.0065 & 0.0321 & 0.9023 & 40.1 \\
\hline $30-34$ & 0.0072 & 0.0352 & 0.8731 & 35.6 & 0.0084 & 0.0412 & 0.8733 & 36.3 \\
\hline $35-39$ & 0.0075 & 0.0368 & 0.8423 & 31.8 & 0.0083 & 0.0408 & 0.8374 & 32.8 \\
\hline $40-44$ & 0.0113 & 0.0547 & 0.8113 & 27.9 & 0.0109 & 0.0529 & 0.8033 & 29.1 \\
\hline $45-49$ & 0.0131 & 0.0636 & 0.7669 & 24.4 & 0.0119 & 0.0577 & 0.7608 & 25.6 \\
\hline $50-54$ & 0.0209 & 0.0993 & 0.7181 & 20.8 & 0.0200 & 0.0952 & 0.7169 & 22.0 \\
\hline $55-59$ & 0.0202 & 0.0960 & 0.6468 & 17.9 & 0.0182 & 0.0869 & 0.6487 & 19.0 \\
\hline $60-64$ & 0.0421 & 0.1905 & 0.5848 & 14.5 & 0.0356 & 0.1634 & 0.5923 & 15.6 \\
\hline $65-69$ & 0.0444 & 0.1998 & 0.4734 & 12.3 & 0.0406 & 0.1843 & 0.4955 & 13.1 \\
\hline $70-74$ & 0.0775 & 0.3246 & 0.3788 & 9.8 & 0.0654 & 0.2809 & 0.4042 & 10.6 \\
\hline $75+$ & 0.1210 & ----- & 0.2559 & 8.3 & 0.1149 & -- & 0.2907 & 8.7 \\
\hline
\end{tabular}


African Population Studies Vol. $23 N^{\circ}$ 2/Etude de la Population Africaine Vol. $23 N^{*} 2$

Table 3c: Male and female life tables based on average 1976-1987 deaths

\begin{tabular}{|c|c|c|c|c|c|c|c|c|}
\hline \multirow[b]{2}{*}{$\begin{array}{l}\text { Age } \\
\text { group }\end{array}$} & \multicolumn{4}{|c|}{ Males } & \multicolumn{4}{|c|}{ Females } \\
\hline & $\begin{array}{c}\mathrm{ASMR} \\
{ }_{5} \mathrm{~m}_{\mathrm{x}} \\
\end{array}$ & $\begin{array}{c}\text { Probability } \\
\text { of dying } \\
{ }_{5} q_{x}\end{array}$ & $\begin{array}{c}\text { Survivors } \\
\text { to age } \mathrm{x} \\
\mathrm{I}_{\mathrm{x}} \\
\end{array}$ & $\begin{array}{c}\text { Life } \\
\text { expectancy } \\
e_{\mathrm{x}}\end{array}$ & $\begin{array}{c}\mathrm{ASMR} \\
{ }_{5} \mathrm{~m}_{\mathrm{x}} \\
\end{array}$ & $\begin{array}{c}\text { Probability } \\
\text { of dying } \\
{ }_{5} q_{x}\end{array}$ & $\begin{array}{c}\text { Survivors } \\
\text { to age } x \\
I_{x}\end{array}$ & $\begin{array}{c}\text { Life } \\
\text { expectancy } \\
e_{x} \\
\end{array}$ \\
\hline $0-4$ & 0.0383 & NA & NA & NA & 0.0351 & NA & NA & NA \\
\hline $5-9$ & 0.0056 & 0.0275 & 1.0000 & 55.3 & 0.0049 & 0.0241 & 1.0000 & 57.1 \\
\hline $10-14$ & 0.0034 & 0.0167 & 0.9725 & 51.8 & 0.0033 & 0.0165 & 0.9759 & 53.4 \\
\hline $15-19$ & 0.0042 & 0.0206 & 0.9562 & 47.6 & 0.0041 & 0.0201 & 0.9598 & 49.3 \\
\hline $20-24$ & 0.0052 & 0.0258 & 0.9366 & 43.5 & 0.0046 & 0.0226 & 0.9405 & 45.2 \\
\hline $25-29$ & 0.0056 & 0.0276 & 0.9124 & 39.6 & 0.0055 & 0.0270 & 0.9192 & 41.2 \\
\hline $30-34$ & 0.0069 & 0.0338 & 0.8872 & 35.7 & 0.0069 & 0.0340 & 0.8944 & 37.3 \\
\hline $35-39$ & 0.0076 & 0.0373 & 0.8572 & 31.8 & 0.0075 & 0.0369 & 0.8640 & 33.5 \\
\hline $40-44$ & 0.0114 & 0.0553 & 0.8252 & 28.0 & 0.0103 & 0.0503 & 0.8322 & 29.7 \\
\hline $45-49$ & 0.0135 & 0.0651 & 0.7796 & 24.5 & 0.0113 & 0.0551 & 0.7903 & 26.1 \\
\hline $50-54$ & 0.0204 & 0.0973 & 0.7289 & 21.0 & 0.0175 & 0.0837 & 0.7468 & 22.5 \\
\hline $55-59$ & 0.0197 & 0.0939 & 0.6580 & 18.0 & 0.0166 & 0.0795 & 0.6843 & 19.3 \\
\hline $60-64$ & 0.0394 & 0.1793 & 0.5962 & 14.6 & 0.0329 & 0.1521 & 0.6299 & 15.8 \\
\hline $65-69$ & 0.0400 & 0.1818 & 0.4893 & 12.2 & 0.0340 & 0.1565 & 0.5341 & 13.2 \\
\hline $70-74$ & 0.0752 & 0.3165 & 0.4003 & 9.4 & 0.0639 & 0.2756 & 0.4504 & 10.2 \\
\hline $75+$ & 0.1315 & ----- & 0.2736 & 7.6 & 0.1240 & ----- & 0.3263 & 8.1 \\
\hline
\end{tabular}

Source: Author's computations based on the 1976 and 1987 censuses of Cameroon

Discussion and Conclusion

This paper employs the generalized growth balance method to estimate adult mortality in Cameroon using data from 1976 and 1987 censuses. Overall, there are indications that childhood mortality improved during the intercensal period. By contrast mortality for those who survived through childhood years apparently stagnated. Two nationwide surveys conducted as part of the worldwide effort, the Cameroon Demographic and Health Surveys (CDHS) in 1998 and 2004 have collected sibling survival information. A comparative assessment of these data alongside similar data for other African countries by Timaeus and Jasseh (2004) estimates the probability of dying between ages 15 and 60 around 1995 at $28 \%$ and $23 \%$ for Cameroon men and women, respectively. These estimates are evidently on the low side compared to those presented in the current study, perhaps attributable to methodological and data differences. The CDHS estimates are much lower for 1990; $18 \%$ and $15 \%$ for males and females respectively. It is informative to examine the direct estimates to see how well they compare with similar estimates from the sibling survival data. Figures $5 a$ and $5 \mathrm{~b}$ present the age-specific mortality rates for men and women aged 10-64 years for the 1976 and 1987 censuses compared with the estimates based on sibling information in the 1998 and 2004 DHS provided in the country reports. The latter estimates correspond to the periods 19891998 and 1998-2004, respectively, while those computed for the census correspond to the mortality situation during the 12 months period preceding each census. 
Martin W Bangha: Estimating Adult Mortality in Cameroon from Census Data on Household Deaths:

Figure 5a: Comparing age-specific death rates for males aged 15-64: 1976-2004

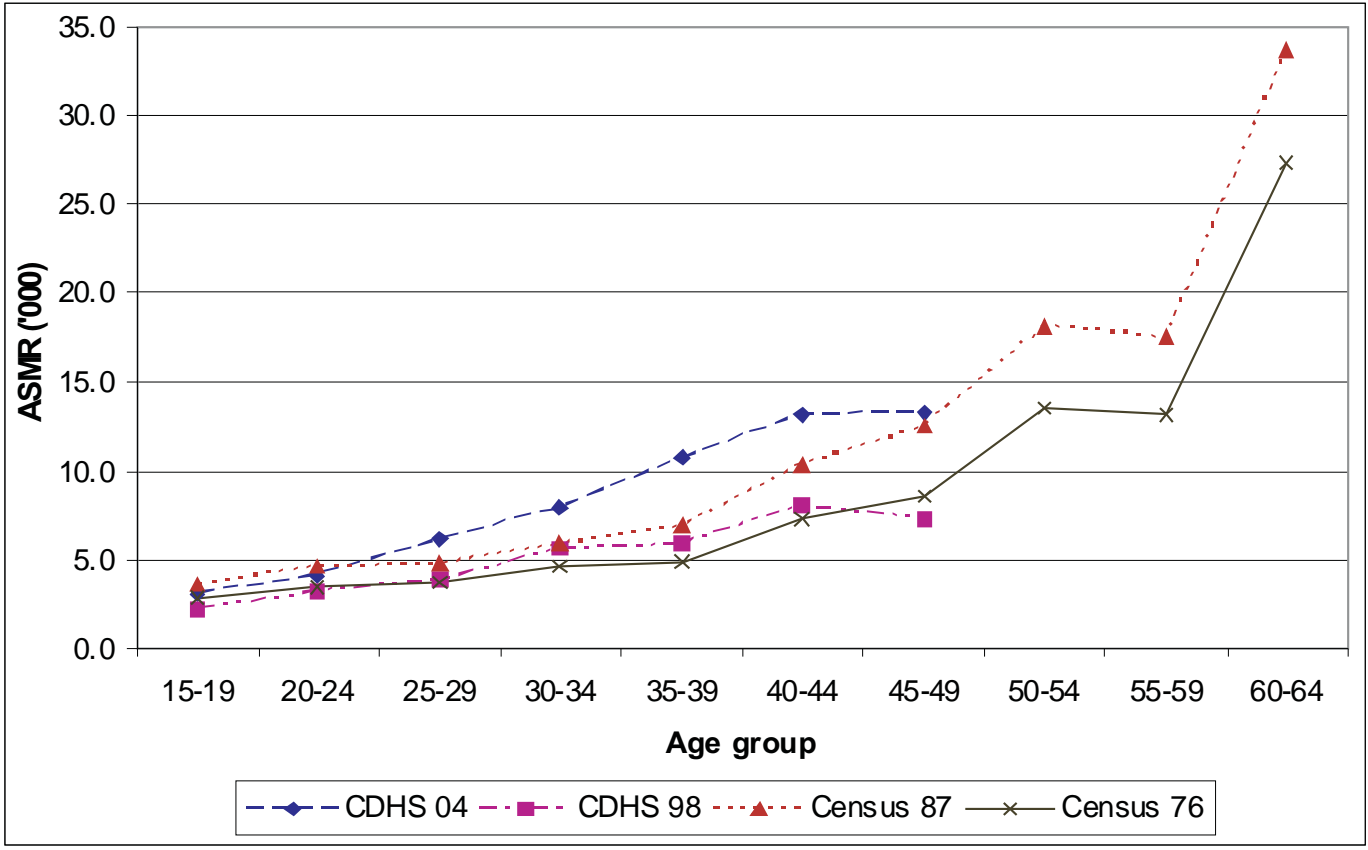

Figure 5b: Comparing age-specific death rates for females aged 15-64: 1976-2004

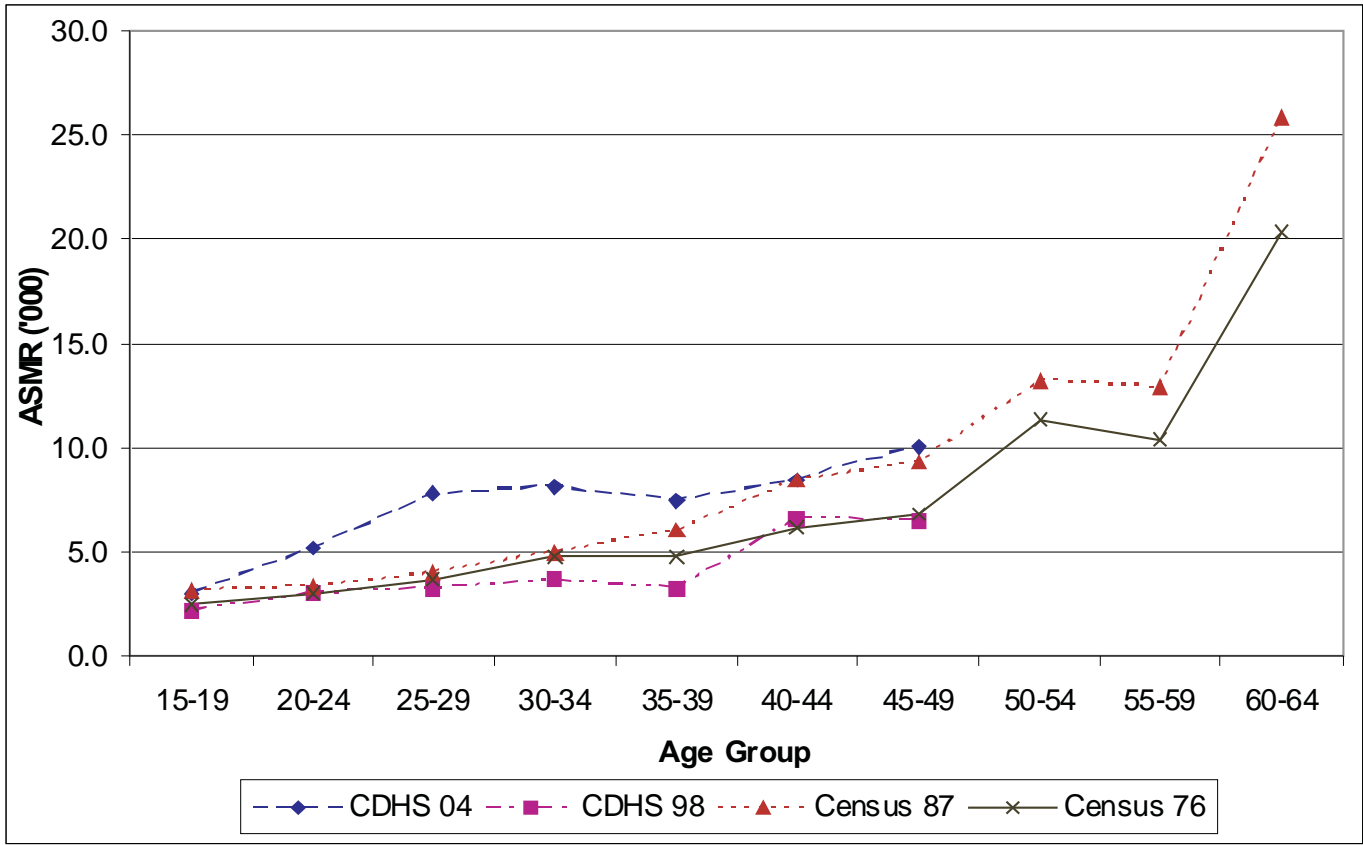

Sources: For CDHS 1998 and 2004, see Fotso et al. (1999) and, INS et ORC Macro (2004) respectively. Otherwise, author's calculations based on the 1976 and 1987 censuses of Cameroon. 
African Population Studies Vol. $23 N^{\circ} 2 /$ Etude de la Population Africaine Vol. $23 N^{*} 2$

For both men and women, mortality rises rapidly with age and rates are consistently higher for males than for females. Compared to the CDHS estimates, the 1987 mortality rates seem slightly higher than rates for 1989-1998 but lower than the rates for 1998-2004. Irrespective of the estimates, there is some general indication of male mortality penalty. In combination with the adjusted estimates presented earlier, the observed estimates also suggest little or no improvement in the adult mortality situation in Cameroon over the last two decades of the 20th century. The situation seems to have deteriorated or stagnated even prior to the onset of the HIV/AIDS pandemic. Based on this comparison, the ages for which mortality seems to have increased barely overlap, but are apparently different for males and females. The increase for males (Figure 5a) seems to be more pronounced in the age range 30-45 years and in the age range 20-35 years for women (Figure 5b). These ages correspond to the peak productive and reproductive adult years. These are also known to be the AIDS years, where the impact is most often pronounced. However, it should be noted that the indication of a pronounced increase at these ages is mostly portrayed by the recent DHS survey conducted in 2004. With sample size issues and other data limitations, more information (from other sources) on adult mortality risks in the country are needed before any conclusive statements can be drawn from these trends on the current levels.
Considering that the first documented AIDS cases in Cameroon were in 1987 (MSP et OMS 1989), this paper provides a baseline assessment of the adult mortality situation in Cameroon. The overall picture from the results is that of a population that experienced stagnating adult mortality between the mid 1970 and mid 1980 . Adult mortality in Cameroon prior to the onset of the pandemic was high by African standards. However, results disaggregated by sex suggest that adult female mortality temporarily improved over the intercensal period. The female mortality advantage translates to a difference of less than three years in the expected remaining years of life at age 15 . The estimated probabilities of dying between ages 15 and 60 imply an overall $15 \%$ excess adult male mortality relative to female mortality. The indication that female adult mortality declined over the intercensal period is consistent with both national and international efforts to curb maternal mortality through the institution and implementation of safe motherhood and maternal and child health $(\mathrm{MCH})$ programs during the period covered by these censuses.

Meanwhile, a potential suspect for the male mortality stagnation for which there is no empirical evidence is the dramatic changes in the sociopolitical and economic environment in Cameroon in the mid-1980s. The relatively poor performance of the Cameroon economy during the early 1980s and the dramatic changes in employment opportunities and other 
Martin W Bangha: Estimating Adult Mortality in Cameroon from Census Data on Household Deaths:

related political changes are probably among the major factors. Mortality and, more probably, morbidity, may have increased as a consequence of the, economic crises, worsening of living conditions and mounting unemployment. Due to data availability, studies relating socio-economic fluctuation and mortality focus mostly on overall mortality. A comprehensive attempt to assess the demographic response to economic shocks in Latin America (Hill and Palloni 1992) show that recession has some expected adverse effects on mortality of vulnerable groups like women, though the mortality responses are quantitatively unimportant compared to historical trend (see also Soares 2007). In the case of Cameroon it is possible to suspect that because men were traditionally the breadwinners, political and economic actors; socio-political and economic shocks of the early 1980s might have induced a differential male-female mortality response. In particular, any negative effect on women might have been cushioned by the corresponding worldwide efforts during this era to curb maternal and child mortality.

\footnotetext{
${ }^{4}$ The economic depres sion that emerged during the early to mid 1980s developed into political crisis in the early 1990s, and was further aggravated by the devaluation of the CFA Franc in 1994, accompanied by the two succes sive salary slashes. In effect, Cameroon happens to be the only country (among a dozen former French colonies in Central and West Africa using the common currency, FCFA) where civil servants had to support the weight of the franc devaluation alongside heavy cuts in salaries. Other nei ghboring countries rather increased salaries to counter the effect of this devaluation.
}

\section{Conclusion}

There are no approximately comparable estimates from other sources that could serve as external checks for our estimates. Nonetheless, the assessment of sibling histories from the DHS (Timaeus and Jasseh 2004) in Sub-Saharan Africa provides estimates for a few countries corresponding to 1985. As mentioned already, these DHS estimates are all on the low side, except for the Central African Republic, a close neighbor to Cameroon, for which the estimated probability of dying between ages 15 and 60 (0.308 and 0.348 for women and men respectively) approach the estimates we obtained in this study. It may appear from this comparison that the census data (more precisely household deaths) overestimates mortality compared to the results of the recent DHS surveys. More recent comparable data or a much longer data series are needed to ascertain the observed trend. The third Cameroon census conducted in 2005, 18 years after the second, is not yet available. It will be interesting to evaluate the situation once this data eventually becomes available. This paper reiterates the usefulness to mortality analysis and policy intervention, of consistently collecting information on household deaths in censuses.

\section{Acknowledgements:}

The author gratefully acknowledges helpful inputs from Emily Hannum, Irma Elo and Tukufu Zuberi on earlier versions of this paper and methodological discussions with John 
Wilmoth, Ken Hill and Kevin Thomas. This research was done a part of the African Census Analysis Project (ACAP) which in collaboration with the Cameroon Central Bureau of the Census and Population Studies (BUCREP) and National Institute of Statistics (NIS) in Yaoundé provided the data for these analyses. ACAP was supported by grants from the Fogarty International Center (TW00004), National Institute of Child Health and Human Development (TW00655-04), Rockefeller Foundation (RF 97013 \#21; RF 98014 \#22), and Andrew W. Mellon Foundation.

\section{References}

Ahmad, O.B., A.D. Lopez, and M. Inoue. 2000. "The Decline in Child Mortality: A Reappraisal." Bulletin of the World Health Organization 78(10):1175-1191.

Ainsworth, M., K. Beegle, and G. Koda. 2005. "The Impact of Adult Mortality and Parental Deaths on Primary Schooling in NorthWestern Tanzania." Journal of Development Studies 41(3):412-439.

Bennett, N. and S. Horiuchi. 1981. "Estimating the Completeness of Death Registration in a Closed Population." Population Index 47(2):207-221.

Bennett, N. and S. Horiuchi. 1984. "Mortality Estimation from Registered Deaths in Less
Developed Countries." Demography 21(2):217-233.

Bhat, P.N. Mari. 2002. “General Growth Balance Method: A Reformulation for Populations Open to Migration." Population Studies 56(1):23-34.

Brass, William. 1975. Methods for Estimating Fertility and Mortality from Limited and Defective Data. Chapel Hill: University of North Carolina Press

Bureau Central du recensement (BCR) 1978. Recensement Général de la Population et de l'Habitat d'Avril 1976 : Analyse Structures par Sexe et Age. Vol II(1), DSCN, Yaoundé.

Cameroun 1992. Démo 87: Résultats Bruts, République du Cameroun. Vol. II Tome 1 et Démo 87: Analyse Préliminaire, Synthèse des Rapports Préliminaires. Direction National du 2éme RGPH, Vol. III Tome 9.

Case, Anne, C. Paxson and J. Ableidinger 2004. “Orphans in Africa: Parental Death, Poverty, and School Enrollment." Demography 41(3):483-508.

Case, A. and C. Ardington. 2006. "The Impact of Parental Death on School Outcomes: Longitudinal Evidence from South Africa." Demography 43(3):401-420.

Easterlin, R.A. 2004. "How beneficent is the market? A look at the modern history of mortality." The Reluctant 
Martin W Bangha: Estimating Adult Mortality in Cameroon from Census Data on Household Deaths:

Economist: Perspectives on Economics, Economic History, and Demography. Cambridge: Cambridge University Press, Chapter 7:101-138.

Fogel, R.W. 2004. The Escape from Hunger and Premature Death 1700-2100: Europe, America and the Third World. Cambridge: Cambridge University Press.

Fotso, M. et al. 1999. Enquête Démographique et de Santé, Cameroun 1998. Bureau Central des Recensements et des Etudes de Population et Macro International Inc., Calverton, Maryland.

Hill, A. 1993. "Trends in Childhood Mortality." Demographic Change in Sub-Saharan Africa. National Research Council, Washington, DC: National Academic Press: 153217.

Hill, K. 1987. "Estimating Census and Death Registration Completeness." Asian and Pacific Population Forum 1(3): 8-13 \& 23-24.

Hill K. and A. Pebley. 1989. "Child Mortality in the Developing World." Population and Development Review 15(4):657-687.

Hill, K. and A. Palloni. 1992." Demographic Response to Economic Shocks: The Case of Latin America." Proceedings of the IUSSP Conference on The Peopling of the Americas, Veracruz 1992 Vol. 3:411-
437.

Hill K. and B. Queiroz 2004. "Adjusting General Growth Balance Method for Migration." Paper presented to the AMDC Meeting, Berkeley. July 2004

Hill, K. and Y. Choi. 2004. "Death Distribution Methods for Estimating Adult Mortality: Sensitivity Analysis with Simulated Data Errors." Paper presented to the AMDC Meeting, Berkeley. July 2004.

Hill, K. and K.J.A. Thomas. 2007. "Evaluating the Performance of Death Distribution Methods for Estimating Death Registration Completeness: Applications to Data from High Income Countries." Presented at the Annual Meetings of the Population Association of America New York March 29-31.

Hill, K., R. Pande, M. Mahy and G. Jones. 1999. Trends in Child Mortality in the Developing World: 1960 to 1996. New York, United Nations Publications.

Institut National de la Statistique (INS) et ORC Macro. 2004. Enquête Démographique et de Santé du Cameroun 2004. Calverton, Maryland.

McDaniel, A. and E. Zulu. 1996. "Mothers, Fathers, and Children: Regional 
African Population Studies Vol. $23 N^{\circ} 2 /$ Etude de la Population Africaine Vol. $23 N^{*} 2$

Patterns in Child-Parent Residence in Sub-Saharan Africa" African Population Studies 11:1-28.

Ministère de la Santé Publique (MSP) et Organisation Mondiale de la Santé (OMS). 1989. "Revue du Programme Quinquennal de Lutte contre le SIDA." Yaoundé, Octobre-Novembre 1989.

Noumbissi, A., A.A. Bawah and T. Zuberi 2005. "Parental Survival and Residential Patterns," Zuberi et al. (eds.), The Demography of South Africa. M.E. Sharpe Publishers, New York: 160-180.

Preston, S.H. 1975. “The Changing Relation between Mortality and Level of Economic Development." Population Studies 29(2):231-248.

Preston, S.H. and K. Hill. 1980. "Estimating the Completeness of Death Registration." Population Studies 34(2):349-366.

Preston, S.H., P. Heuveline and M. Guillot. 2001. Demography: Measuring and Modeling Population Processes. Blackwell Publishers, Oxford.

Shryock, H.S., J.S. Siegel and Associates (eds.). 1976. The Methods and Materials of Demography. Condensed Edition, Academic Press, San Diego.

Soares, Rodrigo 2007. “On the Determinants of Mortality
Reductions in the Developing World." Population and Development Review 33(2): 247-88.

Timaeus, I.M. 1999. "Adult Mortality in Africa in the Era of AIDS." The African Population in the 21st Century. Third African Population Conference, UAPS-NPU, Vol. II, pp.377-395.

Timaeus, I.M. 1991. “Estimation of Adult Mortality in Less Developed Countries: A Comparative Review." Population Index 57(4):552-568.

Timaeus, I.M. and M. Jasseh. 2004. "Adult Mortality in Sub-Saharan Africa." Demography 41(4):757-772.

United Nations. 2002a. Methods for Estimating Adult Mortality. Population Division, DESA ESA/P/WP.175. Preliminary unedited version Www.un.org (accessed October, 2006).

United Nations. 2002b. International Migration Report 2002. ST/ESA/SER.A/220, New York.

United Nations. 2004. World Population Prospects: The 2002 Revision. ST/ESA/SER.A/233, New York

UNAIDS. 2006. “UNAIDS/WHO AIDS Epidemic Update: December 2005 Sub-Saharan Africa 5" www.unaids.org/epi / 2005 (accessed Dec 8, 2006). 
Martin W Bangha: Estimating Adult Mortality in Cameroon from Census Data on Household Deaths: 1976-1987

Walker, N. B. Schwartlander, and J. Bryce. Zuberi, T., A. Sibanda, A. Bawah, and A. 2002. "Meeting International Goals in Child Survival and HIV/ AIDS." The Lancet 360:284-89. Noumbissi. 2003. "Population and African Society." Annual Review of Sociology 29:465-486.

Wilmoth, J.R. 2000. “Demography of longevity: Past, Present and Future Trends." Experimental Gerontology 35(9):1111-1129. 